\title{
Polyphony and Polygraphy: African First-Language Speakers As Learner-Writers at a Private School in South Africa
}

\author{
Muchativugwa Liberty Hove
}

North-West University, Mafikeng

Email: muchativugwahv@gmail.com

\section{Doi:10.5901/mjss.2014.v5n14p319}

\section{Abstract}

The Telkom Foundation, the corporate social responsibility (CSR) arm of the telecommunications giant in South Africa, funded twenty learners from previously disadvantaged schools to enrol and study at a private school called the International School of South Africa (ISSA) in 2008. Upon enrolment, learners took a proficiency test and results thereof indicated they lacked cognitive academic language proficiency (CALP) skills, especially in reading and writing. The current multi-method longitudinal case study used a questionnaire for the participants, consultations with the learners' parents, an examination of the ISSA entry and exit syllabuses, and observations to assess the participants' language needs. Error analysis, together with contrastive analysis, provided the theoretical framework. One finding was that the participants' change-over from mother-tongue instruction to using English as the LoLT had been done prematurely when the learners had not yet acquired sufficient academic cognitive skills. The findings suggest that intervention that could empower the participants and accommodate the learners' transcultural experiences is enhanced through a needs analysis and use of a relevant and efficient syllabus.

Keywords: Polyphony ,Polygraphy , Iterative processes of syllabus design Reflexivity , Linguistic proficiency

\section{Introduction}

In 2007 the Telkom Foundation sponsored twenty learners from previously disadvantaged primary schools in Limpopo, Northwest and the Western Cape provinces in South Africa to enrol and study as boarders at a private school, the International School of South Africa (ISSA) located in the North-West Province. There was a subsequent group of 42 learners from the similarly disadvantaged schools sponsored in 2008. These learners were purposively selected for a longitudinal case study, spanning three years from 2007 to 2011, on language needs and negotiating an efficient syllabus designed for the acquisition of grade-appropriate cognitive academic language proficiency skills (CALP). Development from basic interpersonal communication skills (BICS) to CALP skills (Cummins, 2000) is imagined in this paper as an "iterative process of course and learner literacies development" (Evans, 2011). In the words of Dornbrack (2007:2), "these migrated learners from previously disadvantaged schools experienced financial, social, emotional and linguistic displacement" but they were also being offered an opportunity for integration and nurturing of grade-appropriate academic language skills at a private school.

This paper consequently emerged from the premise that there are at least three manifestations of a syllabus present in each classroom (that of the teacher, the learners, and the practical one that the learners and the teachers work out each day). Varieties of syllabus design are concerned with how a language is learned and how this language is integrated with learners' experiences; hence the critical process in this research was identifying learner needs in the transition of the research participants from impoverished schools to a well-resourced one.

This study elicited the academic language needs of the Telkom Foundation learners through a questionnaire. The construction and administration of the questionnaire was on the understanding that the open-endedness of language acquisition and creativity of language demand a critical focus on the processes of language learning and the strategies and techniques used by the language learners to enable them to move from BICS towards the more challenging CALP (Cummins, 2000). Varying forms of classroom organization and activities pursued to meet the language syllabus have to be centred on the learners' needs as described in their responses to a questionnaire.

Their language needs were compared to the anticipated competence standards measured by Cambridge International Examinations board (CIE), the examination which they were set to write at the end of a four year programme in 2011. 


\section{Research Question}

The research explored whether it was possible to identify, define and explain the academic language needs and challenges of the Telkom learners and also establish whether or not it was possible to develop relevant and efficient syllabus materials to enhance the English language acquisition strategies and skills of this cohort of learners.

\section{Research aim}

Through a description of learner needs and errors, this study aimed to develop a relevant, workable and efficient syllabus for Telkom Foundation learners that would bridge the aspirations of Curriculum 2005 (the outcomes based syllabus used in South African schools), and the expectations of the CIE (Cambridge International Examinations) syllabus.

\section{Background to the Research Problem and Participants}

The environment in which the learners had been taught to succeed through specific methods and approaches in impoverished primary schools was guided by top down syllabus specifications, designed and disseminated as C 2005 in South Africa. These C2005 outcomes were challenged at the ISSA private school in terms of pedagogical orientation, material resources and the teachers who democratised syllabus design. This participatory approach to syllabus design was twin-pronged: to give space for the learners to contribute towards generating ideas for a syllabus to be developed within the framework of the school, and also for the educator to understand the competencies the learners were bringing into the school so that new linguistic challenges could be decided upon. It was an inclusive, participatory approach that sought to underscore the point that syllabus design necessarily mediates and affects the way language is acquired and used. The group enrolled in 2007 had 20 learners: 12 male and 8 female. The second group enrolled in 2008 had 42 learners: 21 male and 21 female. For both groups, L1 was distributed as follows: 39 spoke Setswana, 15 spoke Sepedi and 8 spoke Afrikaans. Early years of schooling therefore implied that English was taught as a first additional language. On enrolment at ISSA, the learners' ages ranged between 13 and 15 years and they were to be taught English as a First language.

Faced with the challenges and possibilities of English language acquisition, a significant number of the learners adjusted their language learning and production strategies in order to integrate in the new school. From observation, phonetic adjustment towards the 'accents' of the teachers and other learners already enrolled in the school became a 'norm' participants had to immediately acquire. These acquisition strategies created an environment characterised by polyphony, a Bhaktinian experience in which the multiplicity of learner languages were in contact with English as a target language (Bhakhtin, 1981). Tsholofelo, one of the research participants, pointed this out in 2008:

The learners in this school speak like whites. I don't know but, eish, ekasi we do not speak like them. You know, sir, when we speak like that, the English of this school at home during the holiday, the friends from our past school, they laugh. They say we are too proud, especially now we are in this expensive school.

The learners' home languages and cultures were regarded as equally important and valid as the target language in their school life (Kumaravadivelu, 2003; Savignon and Sysovev, 2005). The table below shows the profile of the research site.

Table 1: ISSA Research Site - Demographics

\begin{tabular}{|l|l|l|}
\hline \multicolumn{1}{|c|}{ Language profile } & \multicolumn{1}{|c|}{$\begin{array}{c}\text { 450 learners who interacted in English } \\
\text { largely }\end{array}$} & $\begin{array}{l}\text { Diverse language backgrounds: Setswana, Sepedi, isizulu, } \\
\text { Afrikaans, Chichewa, Kiswahili, chiShona, isiNdebele, } \\
\text { Portuguese, French, Igbo, Yoruba }\end{array}$ \\
\hline Teacher: Pupil ratio & $1: 25$ & $\begin{array}{l}\text { Manageable class size and opportunity for one-on-one } \\
\text { interaction }\end{array}$ \\
\hline Print resources & Library and textbooks for each learner & $\begin{array}{l}\text { Learners could source extension material from library and } \\
\text { use departmental libraries }\end{array}$ \\
\hline Electronic resources & $\begin{array}{l}\text { Wi-fi, e-mail and whiteboard technology in } \\
\text { classrooms, computer laboratory for } \\
\text { individual searches and printing }\end{array}$ & $\begin{array}{l}\text { Provided additional scope for notes, demonstrations and } \\
\text { extended resources }\end{array}$ \\
\hline $\begin{array}{l}\text { Learner support } \\
\text { programmes }\end{array}$ & $\begin{array}{l}\text { Homework, additional lessons for } \\
\text { Mathematics and English in the afternoons, } \\
\text { from 1400 to 1530 daily. }\end{array}$ & $\begin{array}{l}\text { Teacher availability throughout the working day, and in the } \\
\text { evenings should need arise for extended consultation }\end{array}$ \\
\hline
\end{tabular}


"Polyphony and polygraphy" therefore seeks to examine the tensions inherent in the spoken and written texts of the research participants as they navigated possible routes towards linguistic modalities and identities that fostered new capacities of interrogating their learning experiences. This article, having established that syllabus design, development and implementation are iterative processes emerging from fact-finding about the learners, proceeds to describe the competencies that the learners brought in, the problems faced by the learners and the results from interviews, together with a sample of errors gleaned from the learners' written work.

\section{Proficiency Levels}

The learners could understand and use context embedded and academically not challenging basic interpersonal communicative skills (BICS) such as everyday expressions and basic phrases aimed at the satisfaction of needs of a concrete type; they could ask and answer questions about personal detail such as where they came from, the people they knew and what they aspired to be in the future; they could interact in a simple way provided the interlocutor talked slowly and clearly. Amongst themselves, it was observed that they could be described as interacting on quite a sophisticated level since they resorted to using home languages - Sepedi, Setswana and Afrikaans - to interrogate and explore their new environment, its culture and the ways that they could adapt in order to succeed academically. The learners could be described as having 'basic user' proficiency skills in English as a second language, but from observation, they also demonstrated sophistication in their use of home languages. It was also observed that for purposes of "group solidarity" 12 of the learners commonly resorted to using Setswana for interpersonal communication, whilst the 8 Afrikaans speakers continued to use their home language especially if they were in their "group." These observations endorse the view by Savignon (2007: 210) that

The need to find new ways of self-expression may be accompanied by feelings of alienation and estrangement. When two or more languages come together, two or more persons come together. And the engagement that follows involves issues of power and identity.

Setswana, Sepedi and Afrikaans - as home languages - express both learner power and learner identity. They were, for the new learners, instruments of estrangement and solidarity, paradoxically.

ISSA is a predominantly English medium school: its clientele is "international" and the discourse patterns are largely in English, although it does not disallow the use of other languages that learners bring into the school. It was clear that the participants needed English language skills that would enable them to understand, encode and decode a range of context-reduced and academically challenging material; skills that would enable them to write and summarize information from different spoken or written sources. The learners were expected to be able to reconstruct arguments and accounts in a coherent presentation, and in the process, express themselves fluently, precisely, differentiating finer shades of meaning, especially in metaphorical and linguistically complex situations. Writing skills such as brainstorming ideas, drafting essays, structuring and evaluating them were critical for these secondary school learners. Contextreduced English language material presented processing challenges that the learners would need to overcome through intensive attention to the language qua language and deliberate efforts to make sense of it. Such CALP skills would enable the learners to ask clarification questions, evaluate and restate information as needed and negotiate solutions to problems (Nunan, 1988). In reading and writing, the learners would ultimately be expected to identify and apply logical connectors in order to express enumeration, exemplification, comparison, summary, addition and inference. As Tarone (1983), Clause and Casper (1983) and later, Canagarajah (2005) contend, learning strategies are attempts to develop linguistic and sociolinguistic competence in the target language. The strategies adopted focus on frequency of linguistic items, the learnability of these and the communicative importance attached to them, by both learner and educator.

\section{The Role of Error Analysis}

Debates in applied linguistics emphasize needs analysis, which is related, as a pragmatic activity, to learner individualization (Widdowson, 2005). This study began with an assessment of learner competencies as measured through an entrance test, developed locally in the Department of English at ISSA, in order to build a profile of current competencies and determine the target needs. The participants' competencies were critical in the design of an initial syllabus and programme of teaching and learning.

Corder (1967/1981) in "The significance of learner errors" suggested that learner errors are important in and of themselves. He further adds that systematic analysis of the errors made by learners facilitates the determination of areas 
that need reinforcement in the teaching In essence, error analysis helps to understand, on a theoretical level, how a learner learns L2. On an applied level, error analysis facilitates intervention, enabling the learner to learn more efficiently by using their knowledge of $\mathrm{L} 1$ for pedagogical ends. Pinpointing the problem becomes diagnostic while making plans to solve the challenges faced by the learner serves a prognostic end. Making plans to solve the challenges could take several pathways, including modifying learning materials and designing efficient syllabus materials to meet the learners' needs. Ancker (2000) legitimately argues that making errors is visible proof that learning is actually taking place, that making mistakes is a natural process of learning and must be considered as part of cognition.

After the initial needs analysis, the process of syllabus refinement becomes recurrent, recursive and, obviously, self-reflexive. As the teaching progressed in the current study, there was a continuous re-interpretation of the learning process and it was established that there were new and emerging changes in the needs of the learners, needs that became clearer from the challenges that the learners faced in accomplishing the linguistic tasks set for the classroom. As Long and Crookes (1993:2) contend, "student-teacher negotiation of content and direction is an integral part" of the teaching approach, it also became evident that the new needs had to be incorporated into the initial syllabus, thereby broadening the concepts and scope of the final version.

Ngwenya (2001:11) observes that every syllabus expresses a paradigm which is a "disciplinary matrix wherein the ideas, the problems and the actual mode of undertaking work will reveal shared and consistent assumptions, beliefs, values and ways of interpreting experiences." The Telkom Foundation learners were doubly disadvantaged in terms of language development: at grade four, they were weaned from mother tongue instruction and introduced to English as a second/additional language; on their enrolment at ISSA they were expected to follow a language programme that would terminate in competency and proficiency assessment benchmarked against English as a first language standard in their Cambridge International Examinations.

\section{A Trajectory for CALP Skills}

CALP skills were strategically elaborated and defined at ISSA under writing and reading. The outline below summarises the anticipated trajectory of learner skills development in English language:

Splitting these further into reading and writing, the secondary school learner, between the second year and third secondary school year, was expected to have appropriated the following skills:

- Differentiating fact from opinion through recognition of specific language markers (such as surface and deep meaning).

- Focused reading in order to draw meanings embedded at the sentence level.

- Understanding metaphorical expression, and therefore demonstrating an ability to differentiate commonsensical, everyday usage from the idiomatic usages; including developed ability to reason why one variation in expression is consciously selected and preferred over another.

- Recognising and, by extension, using macro features of a text such as heading, illustrations, typeface in order to expeditiously get the gist of a text.

- Locating specific pieces of information in a text such as facts, detail, events and relationships (summarising).

- Understanding the importance of 'one's own voice', including the ownership of ideas, sensitivity of thought and expression, particularly the element of empathy (reacting to words and sentences in order to evaluate how a writer achieves specific effects).

- Demonstrating significantly developed spatial and numeracy skills such as interpreting graphs, diagrams, maps and flow charts (Ferris, 2002; Hove, 2012).

\section{Methodology}

To answer the research question a qualitative, exploratory, descriptive and contextual design was used. The investigation was characterised by a multi-layered mixed method approach to data collection: semi-structured interviews, a questionnaire for the learners on their needs, observation of the learners on their progress and approximations to the competency and proficiency targets and continuous feedback from the learners on new and emerging task challenges.

\section{The instruments}

The entrance test administered consisted of four sections: a comprehension passage with ten questions that sought to 
assess recall, inference and word substitution skills; a second section with 10 questions that asked the learners to complete sentences using appropriate adverbs; a third section with 10 questions that asked the learners to identify spatial relationships between places and people. The fourth section was a composition, worth 20 marks, based on the experiences of the learner: a page about 'Me.' Here, the learner was expected to give a vivid biography through using simple, compound and complex sentences in a vocabulary range appropriate for the task. Simple clarity and correctness in expression was acknowledged and scored as indicative of basic competence while ambitious vocabulary and varied, sophisticated use of sentence structures were given a high rating in the assessment memorandum.

\section{The participants}

Eight participants spoke Afrikaans as their first language; ten spoke Setswana, six spoke isiXhosa and two spoke sePedi. The learners also indicated they spoke other languages besides their home languages: ten spoke English (with one indicating "but not accurately"). Their ability to read and write in their home language was not fully developed. Not surprisingly, they could only write the most basic expressions in English. Their immersion in a programme of language study and skills development that would ultimately assess them on English first language guidelines was guided by the fact they could be second language users of English but they were not second rate learners.

\section{Interviews with the learners' parents}

The semi-structured interview technique of gathering data was used because of its natural advantage of the richness of the description that emerges. This research obtained in-depth information about the learners and how they performed in primary school, directly from the parents and guardians. The learners themselves were motivated to contribute additional information because someone, in the form of the researcher, was taking a personal interest in their learning processes.

An initial field trip was undertaken in 2007 to gather first hand information on the location, amenities and resources of the schools from which the learners funded by the Telkom Foundation came. This field trip was also intended to have informal interviews with the parents and guardians of these learners on their feelings towards their children's language, the sponsors and the new school their children were attending. It was crucial to measure the attitudes of the parents towards ISSA, especially with regards to the integration of their children and the progress reports that had been forwarded to them at the end of the term. A key interest area was in the languages used by the learners: the home language and the additional language, especially the frequency of English usage outside the classroom and school environment.

I intended to establish firstly what language the learners used commonly at home; and then secondly define and describe the place and function of English in the same space. I wanted to establish the attitudes of the parents to this additional language, which, in the social and economic climate of South Africa, apparently enjoyed a higher status than the home language (Hove, 2012). The national constitution provides for parity and equality of the languages, creating a facile impression that in whatever sphere of social and economic intercourse the eleven official languages would be regarded equally.

Polokwane is approximately $665 \mathrm{~km}$ from the International School of South Africa and Toronto school is $27 \mathrm{~km}$ outside Polokwane. There is relatively developed infrastructure at the school and all the classrooms are standard. The community is quasi-urban, with underdeveloped shanty dwellings around. The beneficiaries of the Telkom Foundation came from this poor polyglot background.

Three of the parents I interviewed were very impressed by the progress of their children so far. They spoke highly of the staff and administration for efforts made to fully integrate their children into the ISSA school community. One of the parents said she was particularly delighted that her daughter had been selected to play for the school Korfball team in Holland over the holidays, a sport hardly known in Polokwane. This particular learner had made distinct progress in her verbal skills and the written expression is fairly firm.

Another parent was worried about the slow progress her son was making in English and she was aware of his limitations and challenges, especially in written English, dating from his primary school years. She wanted her son to be further assisted in order to make more tangible progress in all his academic areas. The only male parent interviewed expressed satisfaction about the progress of his son at the new school and appreciated the bursary funding: it lightened his responsibilities and he could focus on other pressing demands.

I talked to one guardian whose child had serious disciplinary problems. She worried that her son would lose the sponsorship if he continued to be a problem. She stressed that she had admonished her son and hoped that the school would be firm in dealing with him without, of course, jeopardising his chances of retaining the bursary. She had severe 
marital problems and was visibly from a struggling background. She indicated that progress in both English and Mathematics for her son could possibly be impeded by his disciplinary problems and lack of enriching learning resources.

I interviewed more parents at another school, called Disake School, 31km outside the small town of Northam, $380 \mathrm{~km}$ from ISSA. It has a mere two classroom blocks for middle school. The access road to the school is in a poor state of disrepair. The tiny village of Disake is made of make- shift tenements. A few standard houses stand out. There was palpable crippling poverty in the community and only four parents accompanied their children, out of a possible twenty. Two of the parents could not communicate in English and self-consciously avoided both the informal and structured interviews. Only one parent, a teacher herself, spoke to this researcher about the progress of her child. She expressed extreme delight that her daughter had the opportunity to be at ISSA. She revealed that she was aware of the teeming problems her daughter faced academically and hoped that the teachers in the school would do all in their power to make her succeed. The learner in question struggled with basic sentence construction and had huge problems in spelling correctly. Sentences remained on the simple and basic compound level, relying invariably on "and" as a compounding conjunction. Her spoken language had improved significantly and she could communicate with a degree of satisfactory, simple clarity (Hove, 2012).

A female teacher from Disake who had taught the beneficiaries the previous year when the beneficiaries were in their first year of secondary school was also interviewed. She showed a lot of happiness for the sponsorship and continued to indict all within earshot that the beneficent gesture of Telkom was, to quote her, "a lifeline that should never be forgotten." She also indicated that Disake School had arranged a meeting with the chief executive officer of the Telkom Foundation where their progress reports were discussed by the parents, teachers at Disake School and the beneficiaries. What emerged was the concern in this school that the benefactors must use the opportunity to its fullest and never slacken in their efforts. There was, according to the teacher, a need for the learners never to let down Disake and the learning experiences gained at the school, its teachers and the parents who had made it possible for the learners to be where they were at this point: the International School. The teacher was echoing the words of Babalwa, one of the research participants:

"All I need is to go to a school where teachers are fun and supportive, to [learn] and play with friends and come home to a safe place and a happy mom. I will then become anything in life - anything I like" (My emphasis).

This teacher also revealed that one of the learners had shown very little progress and had suggested that due to his literacy challenges, he would rather take another year at the old school. Only after a lot of counselling and persuasion did he come back for the return trip to finish the term, and possibly continue on the programme if satisfactory progress was evident. This particular learner had also lost both parents in a very short space and apparently had never fully reconciled himself to this tragedy. Progress in all his subjects was worrisome as often he wrote with neither cohesion nor coherence.

One learner was late for the bus and when I tried speaking to his grandparent, it was evident that he could not express himself in English unless I brought in a translator to facilitate the interview.

This trip made three things evident:

- The majority of the learners use their home language in all their communication needs and so they have hardly any practice in English outside the classroom.

- On the return trip, all the learners spoke to each other in their home languages: English is the language of the classroom. It has no space in their day to day interaction. The learners respond in English only when spoken to in that language. Unless reinforcement of another format was instituted, challenges of proficiency in articulation and competence in writing would continue.

What was most encouraging in the majority of the learners was that they looked forward to the opening of school for the third term: they hoped to achieve better results in English and across the curriculum than they had during the second term. For many of the learners, ISSA had become a second home...and better. For many too, results in the aggregate passes were a lot better than in the first term when they were - logically - awed and overwhelmed by the ecology of the new school and its practices.

\section{Learner Questionnaires}

In their responses to a questionnaire the learners pointed out their needs in academic English and these have been grouped in this study as 'global' and 'microcosmic' for purposes of discussion:

- Gauging from your English language performance so far, what do you need this language for? 
12.1 A selection of their responses is given below:

I. Writing good and effective compositions

II. Passing language tests by understanding specific questioning techniques and applying the correct answering formats

III. Using English across other subjects in order to read with understanding

IV. Writing with economy and precision in summary work

V. Winning the reader's attention in extended writing by developing an awareness of stylistic variety, the linking of sentences and paragraphs

VI. Structuring information (to make a point; make a concession, introducing a new idea/topic and presenting illustrations or examples)

- Gauging from your reading abilities and challenges so far, what would you say are the benefits of efficient reading in English?

12.2 A selection of their responses is given below:

I. Reading texts beyond direct reference (i.e. beyond extracting facts)

II. Reading to offer explanations and relating different parts of a passage to other segments in order to be able to offer opinion and evaluation

III. Identifying and learning appropriate words and extending vocabulary

IV. Identifying and using various sentence types: simple, compound and complex; topic and terminal sentences.

\section{Results from the Entrance Test}

The learners showed that they had problems with command terms used in setting questions in English language entrance test: describe (tlalosa), discuss (atlatla), argue (ngangisano/ngangisa), say (bua), state (bega), analyse (tlatlosa/sekaseka) and explain (tlalosa). Describe and explain, like "say" and "state", share the same command term in seTswana L1 and Sepedi though they mean different strategies altogether in English and this could be a source of problems with the tasks that the learners are expected to accomplish.

\section{Intervention}

Following on the concept of "iterative processes of syllabus design", this research incorporated specific command terms in order to accentuate learners' understanding of the English First Language question demands. For writing effective, coherent and cohesive compositions, focus was directed at re-ordering jumbled sentences in an extended piece. This was later reinforced by specific focus on parts of speech such as the function and effect of nouns, adjectives, verbs and adverbs in various sentence types. Connectives were identified and explored in order to structure information to:-

- Make concessions: however, in as much as, besides, admittedly, in acknowledging this point, until

- Introduce a new concept/point/topic: notwithstanding, in addition, furthermore, critically, most importantly, there can be only one conclusion; and

- Present illustrations and sequences: from the preceding point, as can be seen from, initially, consequently, finally, considering all of these.

In reading to offer explanations, and relating different parts of a passage to other segments in order to offer evaluative comments and accents, the syllabus developed in situ focused on a generic question at IGCSE level. To assess stylistic and lexical awareness, the generic question asks: "By selecting words and phrases from this extract, comment on the effects that the writer creates." Assuming a positive Mathews' Effect in the reading capacity of the learners, such a question directs the learners to specific lexical and stylistic selections from a text. The research participants attempted to comment on the impact of nouns, the strength of the verbs, the suitability of adjectives and these extended skills to word substitution, including synonyms and antonyms.

\section{Lessons from the Proficiency Test}

The researcher decided on introductory and bridging topics based on the performance of the learners in the entrance test. One of the most significant weaknesses that the test revealed related to basic grammar and there emerged a need 
for orientation of the initial tasks in the syllabus selection, specification and sequencing towards a synthetic syllabus. This addressed the shortcomings in the linguistic organization of the intended syllabus. This problem was approached from the understanding that linguistic intelligence and capacity requires the learner to argue, persuade, entertain, instruct and play with words. This capacity entails understanding the syntax and semantics of the language, ability to recall and, most importantly, 'metalinguistic analysis.' The focus in the classroom practice and the philosophical orientation of the syllabus acknowledged the learners' variety of experiences, skills and sociocultural settings that are critical in their identity formations as all these would be instrumental to academic language learning. Stuart Hall (1998) partially describes such an experience where "learners spoke from a particular place, a particular history, out of a particular experience, a particular culture."

\section{Selected Corpus of Learner Errors from the Longitudinal Study}

One of the most challenging problems in the analysis of learner errors is that such an enterprise involves problematic choices at all stages. When identifying, classifying and explaining an error, the focus is only on the way it impinges on meaning and flouts the rules of grammatical correctness rather than a critical reflection on the unobservable, anguished processing of language in composing. Even if focus is on the logical progression of thought rather than the error qua error (Dulay and Burt, 1982), the issue of error density impeding meaning remains unresolved in identifying and correcting errors.

From compositions submitted for marking and feedback, the following 'errors' were noted:

1. My hobby is to play tennis.

(Failure to use the present progressive tense and relying on the simple present tense; error stems from problems with the gerund and infinitive form 'to')

2. The person I like who sing is Beyonce.

(Error in subject-verb concord; and failure to use modals)

3. When I come back from school I do my homeworks.

(Homework is uncountable in English; it is countable in SeTswana, the home language: the confusion in this regard generates the error).

Ironically, there are a lot of uncountable nouns in English that have 'gained' plural form and are quickly becoming acceptable: publics; peoples; ethnicities etc.

4. The thing that makes me want to be a social worker is because I see how people suffer especially old people living with their grandchildren they don't get grant for the children.

(Error stems from an overgeneralization: 'The thing...' makes perfect sense in MT SeTswana but subject should be reason in this case and the sentence must have begun 'What makes me...' The second half of the compound clause confuses subjects: 'old people' and 'grandchildren.' This error falls under blind agreement as 'grant' should be preceded by an article [any] and take on plural form)

5. I want to have two children, latest car and the latest cell phone.

(This is another case of blind agreement. The context of the sentence is a hypothetical situation: in the future I would prefer to have two children. 'I want' is an incorrect use of the scale of certainty and the modal becomes wrong)

6. I am going to buy my mother a house with my first salary and going to send my sister and brother to the college.

(As in sentence 5, an illogical probability is evident in 'am going to buy' where the intention is to communicate a less definite scale of certainty, such as 'I would love to/like to buy my mother a house. A definite article 'the' is used to indicate another projection about future action for the brother but there has been no reference to any college earlier on to merit a definite article)

7. I really take my perents serous because without them where will I have been.

('serious', like many other words with 'ie' and 'ei' spelling is wrongly spelt and presents a big challenge. 'Parents' in Black South African English takes an inflection of the 'e' after ' $p$ ' instead of 'ae' and the aural quality of that inflection could be source of the spelling error. Ngwenya (2001:204) mentions the problem with wh- indirect questions and submits that this is not a frequent problem. In this research, a significant number of errors in suppression of the inversion rule were identified)

8. My hobbies are singing (I think and my friends say I have a wanderful voice).

(Subject-verb concord error; phonological aural-oriented error in the spelling of 'wonderful)

9. When I see somebody that has no money to buy food I eat my lunch whith him at school. 
(The problem here is with constructing a hypothetical conditional sentence made up of two clauses. The biggest problem is in handling the tenses for the two clauses to make sense of the hypothesis being submitted. There is also a problem in using 'when' for 'if' at the start of the first clause)

10. When we right exams I stay carm and I relex.

('Write' 'calm' and 'relax' are wrongly spelt, and this could be a problem stemming from overgeneralization of the phonetic and spelling rules)

11. When I have no money I just ask my frends to borrow me.

'Borrow' and 'lend' have one lexical item in SeTswana; the two acts in English language are a major source of confusion for the ESL learner and the intended sense can only be discerned from the context of use.)

12. I don't like to fight if I fight I go to thet person and I say I am sorry then me and thet person we became friens agen.

(Phonological elements are evident in the spelling slips here. Individual word sounds, syllable structure and intonation could account for 'thet', 'agen' and 'serous.')

The instances of error highlighted here endorse the view held by functional linguists that at least certain elements of grammar need explicit teaching of grammar rules and a corrective feedback methodology. Evidence in the errors suggests that learners have to be explicitly taught where in a sentence to put an adjective, adverb or how to invert a question. This suggests that structures and forms that exist in L1 but not in L2 (and vice versa) require explicit instruction. It could be a daunting task to insist on the use of extensive grammatical terminology, organised structure by structure, but suffice to submit that when such errors occur with marked frequency in a learner's approximation to academic English, this study, in the classroom delivery, mapped out situationally appropriate structural patterns as comprehensible input.

\section{Competencies Anticipated}

It has been argued that each syllabus design is an ideal that is hinged on promise (Ngwenya, 2011). Theory and practice are therefore largely integrated into this pedagogical vision of possibilities. Based on the task syllabus model and the framework developed by Anderson (1989:178), the current intervention syllabus aimed to activate acquired prior knowledge and synchronise this with new capacities in a bid to extend language competency. It also aimed at developing the vocabulary of the learners from their entry levels and for fluent reading that enhanced comprehension. Learners' reading strategies were verified through graded reading passages that in turn helped to establish the reading levels of the research participants and a summative evaluation of progress was made after the development of the syllabus proposal.

The simple sentences below were given for learners to enhance visually - and the verbs given in italics were some of the possibilities that they offered:

- Siphiwo ran (sprinted, dashed, trotted, wobbled).

- The dog barked (yelped, whimpered).

- $\quad$ The soldier entered the house (marched into, strode into).

In addressing the visual and narrative beat, students in this research were asked to express how characters speak, and they offered: shrieked, muttered, said softly, barked, growled, muttered, moaned and whined. This vocabulary range and its usage in the learners' constructions facilitated a new recognition of what they could offer in terms of writing more efficiently and impressively.

\section{The Reading Curriculum Component}

This empirical study established the linguistic resources and the challenges that the research participants brought into the research site. It is submitted that the task, as an activity carried out as the result of processing and understanding language, provides a purpose for classroom activity. Also considering the historical disadvantages that the research participants experienced in their previous schools, particularly under-resourced schools, rote learning and lack of sufficient reading materials, this syllabus sought to redress inadequacies through a carefully planned remedial and integration programme of both intensive and extensive reading. The task-based approach, being in itself hybrid in orientation, blends the "explicit teaching conventions of language and literacy" (Parmegiani, 2009:100). Embedded in the hybridity of the teaching-learning approaches recommended, it is important to ensure that their reading, appropriation and increasing expertise in English is complemented by making sufficient connections with their own mother tongue literacies (Pennycook, 1994; Canagarajah, 2005). 


\section{Intensive Reading Unit: Summarizing information from Texts}

\subsection{Objectives}

By the end of the unit, learners should be able to:

- read texts set as comprehension in order to select specific points

- list in hierarchy the points selected for the summary draft

- write a summary of the text using own words

\subsection{Content}

- Two texts, one literary and the other non-literary, from a magazine and a short story anthology, based on contrasting themes

\subsection{Learning tasks}

- Identify and comment on a text's explicit or implicit opinions and prejudices though careful reading of what is voiced or unvoiced

- Select a specified number of summary points

- Set out and use appropriate connectors to link the summary points

- Paraphrase some parts of the summary text

- Edit the points for grammaticality

\subsection{Assessment}

- Note-making assessed as a skill

- Connectors assessed to establish flow and coherence of summary

- Use of own words assessed as indication of vocabulary range

- Use of past tense and reporting voice assessed to check understanding

- Final write up assessed for comprehensiveness of points covered

In order to incorporate the views of the learners in the proposed syllabus, a questionnaire was administered in 2008 (year 2 of the study): one question sought to establish what aspects in composition writing the learners felt they should get the most feedback. The table below indicates the responses of the Telkom learners:

Table 1: Aspects that learners feel ought to be corrected in composition writing

Question: In your composition work, tick the aspects that you strongly feel your teacher should offer corrective feedback:

\begin{tabular}{|lc|}
\hline \multicolumn{1}{|c}{ Aspect to be corrected } & Total responses \\
Content and storyline in my composition should be corrected & 9 \\
Relevance of my writing should be assessed & 8 \\
Technical aspects such as spelling, grammar and punctuation & 14 \\
Technical aspects such as subject-verb concord & 11 \\
Technical aspects such as misuse of words and other vocabulary items & 11 \\
Only those aspects that affect the meaning of the writing & 7 \\
All aspects of the writing should be corrected so that the product is perfect & 11 \\
\hline
\end{tabular}

The results show that the learners are concerned about structural elements of the language. They would want their work corrected if they misuse words, if the subject verb pattern is discordant and if their spelling and grammar are not accurate. Those in the minority feel that their work should be corrected for content, relevance and overall impression of the composition. This finding is important in two respects: the majority of the learners are apparently convinced that perfection in technical aspects would contribute significantly to the communicative force of their writing; and as a consequence these aspects should be taught explicitly to avoid similar errors.

Correction, in its very nature, is a form of inductive grammar teaching: it encourages the learner to adjust the 
conscious rule the learner is using or to try to discover a correct rule. This submission by the learners also coincides with the assessment criteria for English as a first language where technical correctness is a descriptor of language competence. Those in the minority (7 respondents) feel that content overrides technical accomplishment: it is the import of the composition (narrative, argumentative or descriptive) that is crucial. These findings should be considered in the design of an efficient and relevant task-based syllabus synthesised from the structural and communicative paradigms. Such an understanding takes into consideration the submission by Barry McLaughlin (2001:5) that

proficiency in the more abstract and disembodied academic language [is] needed...The [learner] needs to learn what verbs....and synonyms ....and antonyms are... [so that they] learn to deal with abstract meanings.

The construct of polygraphy, the interface of L1 and L2 in the written products of the learners, provides an important framework for the design and development of the task-based syllabus proposed in this paper.

\section{Conclusions}

Janks (2010) posits that the most pressing problem is to find a way of incorporating a World Englishes - English as a lingua franca- perspective into testing. In the same spirit of argument with Canagarajah (2005), Janks suggests that solving this problem involves devising the means to distinguish between error and the intelligible local variety of English in order to enable testers to recognise systematic forms from "outer and expanding circle Englishes" (Kachru, 1987) as correct where they differ from inner circle forms. This practical problem manifested itself in the classroom and strategic solutions involved finding ways of identifying accommodation so that learners would be able to adjust their English for the purposes of promoting intelligibility for an interlocutor without the risk of being penalised because their speech or writing did not approximate to native speaker norms. In order to overcome this there is need to maximise the use of English inside the classroom - as medium and object of instruction. The interface of semantic and pragmatic meaning, as suggested by Ellis (2006:3) was exploited in this context as the learners explored expression of their implicit knowledge of intention but faltered in accuracy.

Retrospective sequencing of syllabus items informed the ultimate task-based syllabus, modelled upon the Long and Crookes prototype. The resultant syllabus suggested a number of worlds in dialogue, on the psychological, pedagogic and sociological levels. The mother tongue was roped in to process new knowledges in the second language, especially on the structural and ideational levels - what this paper perceives as the polyphonic aspect. BICS had to be extended to the more macrocosmic CALP skills and this process of skills upgrading had implications for teaching materials, order of presentation and emphasis over specific syllabus items. Variations in the grammaticality of constructions were understood as approximations rather than egregious faults, more specifically in the marking of verbs for tense and mood - what this paper has termed the polygraphic element. The processing of knowledges through the higher order CALP was not always successful or easily measurable, but the initiated process of dialogue between the world of the learners and the world of the educators enhanced the resolution of impeding obstacles on the research participants' journey towards competence.

\section{References}

Anderson, N.J. 1989. Individual differences in strategy use in second language reading and testing. Modern Language Journal 75, 460 472.

Ancker, W. 2000. Errors and corrective feedback: Updated theory and classroom practice. English Teaching Forum. 38(4), 20-24

Bhakhtin, M.M. 1981. Discourse in the novel. In C. Emmerson and Holquist, M. (Ed. And trans.) The Dialogic Imagination. Austin, TX: University of Texas Press.

Bhatia, V. 1997. The power and politics of genre. World Englishes 16, 359-371.

Brown, D.B. 1994. Principles of language learning and teaching. Third edition. New Jersey: Prentice Hall.

Bygate, M. 2005. "Applied linguistics: A pragmatic discipline, a generic discipline?" Applied Linguistics 26, 568-581.

Canagarajah, A.S. 2005. Resisting Linguistic Imperialism in English Teaching. OUP: Oxford.

Clause, and Casper, 1983. "Do language proficiency levels correspond to language learning strategy adoption?" In Gharbavi, A. and Mousavi, S. 2012. Journal of English Language Teaching, Vol5. No. 7.

Corder, S. P. 1967/1981. Error analysis and Interlanguage. Oxford: Oxford University Press.

Cummins, J. 2000. Language, Power and Pedagogy: Bilingual Children in the Crossfire. Clevedon: Multilingual Matters.

Dornbrack, J. 2007. Reflecting on difference: an intervention at a public high school in post-apartheid South Africa. Journal of Education, No 41, 2007.

Dulay H, AND Burt, M. 1982. "A new perspective on the creative construction process in child second language acquisition." Language 
Learning 24: 253-78

Ellis, R. 2006. Second language acquisition research and language teaching. Oxford: Oxford University Press

Evans, R. 2011. "Preparing pre-service teachers for multi-lingual classrooms - designing a multiple African language module." Journal for Language Teaching, Volume 45 Number 2, 2011: 69-83.

Ferris, D. 2002. Treatment of error in second language student writing. Ann Arbor: University of Michigan Press.

Hall, J.K. 2002. Teaching and researching language and culture. Pearson Education: London.

Henry, S. Gardyne, B. and Burger, L. 1988. English in Context. Pretoria: Macmillan Education.

Hove, M. L. 2010. Polyphony and polygraphy: African first language speakers as learner writers at a private school in South Africa. LSSA/SAALA/SAALT Conference, UNISA.

Hove, M, L. 2012. Academic skills and linguistic power: Negotiating a syllabus for the acquisition of multi-faceted literacies in English. Unpublished PhD thesis. North-West University.

Janks, H. 2010. Literacy and power. London: Routeledge.

Kachru, B. 1987. World Englishes: Approaches, issues and resources. Language Teaching 25, 1-14.

Kumaravadivelu, B. 2003. Beyond methods: Macrostrategies for language teaching. New Haven and London: Yale University Press.

Legukte, M. and Thomas, H. 1991. Process and experience in the language classroom. Harlow: Longman.

Leung, C. and Teasdale, A. 1998. "Standards-based approaches to the evaluation of ESL instruction." In Nunan, D. 2007. Springer international handbook of education 1. Volume 15, p. 424.

Long, M.H. AND Crookes, G. 1993. 'Three approaches to task-based syllabus design.' TESOL Quarterly 26, 27-56.

Matsuda, P.K. 2003. 'Process and post-process: A discursive history.' Journal of Second Language Writing, 12, 65-83.

Mclaughlin B. 2001. Theories of second language learning. London: Routeledge.

Ngwenya, T.L. 2001. Designing an English Syllabus for First-Year Law Students. Unpublished PhD Thesis, University of Potchefstroom: Potchefstroom.

Nunan, D. 1988. The Learner-Centred Curriculum. Cambridge: Cambridge University Press.

Parmegiani, A. 2009. The power of English and academic literacy: Students' perceptions and theoretical, political and pedagogical implications. A case study of students at the University of KwaZulu-Natal. Doctor of Philosophy thesis. The City University of New York.

Pennycook, A. 1994. The cultural politics of English as an international language. London: Longman.

Sadler, R.K. AND HAYLLAR, T.A.S. 1984. Secondary School English. Macmillan Education: Claremont.

Savignon, S.J. AND SYSOVEV, P. 2005. "Cultures and comparisons: Strategies for learners." Foreign Language Annals 38, $357-365$.

Savignon, S.J. 2007. Beyond communicative language teaching: What's ahead? Journal of Pragmatics (39) 2007: 207-220.

Selinker, L. 1972. Interlanguage. International Review of Applied Linguistics, 10, 209-231.

Skehan, P. 1998. A Cognitive Approach to Language Learning. Oxford, UK: Oxford University Press.

Suter, C. 2001. "Describing and evaluating a syllabus in a context of compulsory secondary schooling." University of Birmingham Assessment Task, Birmingham.

Tarone, E. 1983. "On the variability of interlanguage systems." Language Learning 29/1: 181-191.

Wallerstein, N. 1983. Language and Culture in Conflict: Problem-posing in the ESL classroom. London: Addison-Wesley.

West, R. 1994. "Needs analysis in language teaching." Language Teaching. Vol.27. Number 1. p 1-19.

Widdowson, H.G. 2005. "Perspectives on communicative language teaching: Syllabus and methodology", in Alatis, J (Ed), 2005: Strategic interaction and language acquisition - Theory, practice and research. Washington: Georgetown University Press. 